\title{
Unrelated to Intervention
}

National Cancer Institute

\section{Source}

National Cancer Institute. Unrelated to Intervention. NCI Thesaurus. Code C53256.

A characteristic used to qualify the adverse event as clearly not related to the medical intervention. 